\title{
Plasma atrial natriuretic peptide concentrations in horses with heart disease: A pilot study
}

\author{
Trachsel, Dagmar S ; Grenacher, Beat ; Weishaupt, Michael A ; Schwarzwald, Colin C
}

\begin{abstract}
Atrial natriuretic peptide (ANP) is a cardiovascular biomarker that might be useful in assessing the severity of cardiac disease in horses. Plasma ANP concentrations $(\mathrm{Cp}(\mathrm{ANP})$ ) were compared between horses with heart disease but normal chamber size and function (Group $A ; n=6$ ), horses with heart disease associated with left atrial (LA) enlargement, LA dysfunction, and/or left ventricular (LV) enlargement (Group B; $n=5$ ), and horses with no clinically apparent cardiovascular disease (Group C; n=13). The median (min-max) for $\mathrm{Cp}(\mathrm{ANP})$ was significantly higher in Group B (53.5 (36.0-70.7) pg/mL), compared to Group A (12.5 (6.3-19.8) pg/mL) and Group C (13.4 (7.2-34.0) pg/mL). Backwards stepwise multiple linear regression showed that $\mathrm{Cp}(\mathrm{ANP})$ in horses with heart disease was related to LA dimensions, but not to LV size, LA function, and LV function. The results indicated that $\mathrm{Cp}(\mathrm{ANP})$ in horses might be useful in detecting LA enlargement and that $\mathrm{Cp}(\mathrm{ANP})$ could be related to the severity of cardiac disease. Larger prospective studies are necessary to confirm these results.
\end{abstract}

DOI: https://doi.org/10.1016/j.tvjl.2011.06.035

Posted at the Zurich Open Repository and Archive, University of Zurich

ZORA URL: https://doi.org/10.5167/uzh-61373

Journal Article

Originally published at:

Trachsel, Dagmar S; Grenacher, Beat; Weishaupt, Michael A; Schwarzwald, Colin C (2012). Plasma atrial natriuretic peptide concentrations in horses with heart disease: A pilot study. The Veterinary Journal, 192(2):166-170.

DOI: https://doi.org/10.1016/j.tvj1.2011.06.035 
Provided for non-commercial research and education use. Not for reproduction, distribution or commercial use.

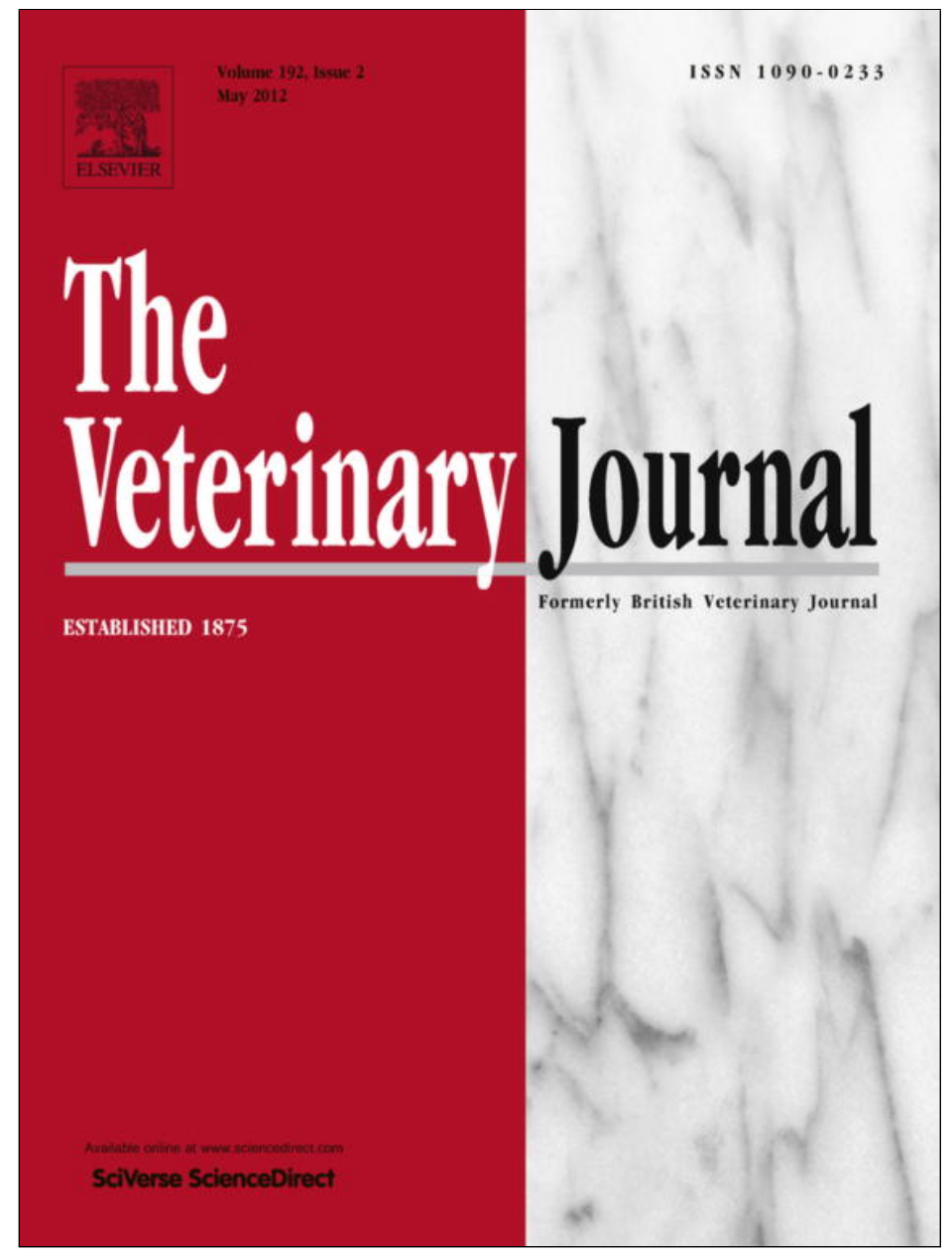

This article appeared in a journal published by Elsevier. The attached copy is furnished to the author for internal non-commercial research and education use, including for instruction at the authors institution and sharing with colleagues.

Other uses, including reproduction and distribution, or selling or licensing copies, or posting to personal, institutional or third party websites are prohibited.

In most cases authors are permitted to post their version of the article (e.g. in Word or Tex form) to their personal website or institutional repository. Authors requiring further information regarding Elsevier's archiving and manuscript policies are encouraged to visit:

http://www.elsevier.com/copyright 


\title{
Plasma atrial natriuretic peptide concentrations in horses with heart disease: A pilot study
}

\author{
D.S. Trachsel ${ }^{\mathrm{a}, *}$, B. Grenacher ${ }^{\mathrm{b}}$, M.A. Weishaupt ${ }^{\mathrm{a}}$, C.C. Schwarzwald ${ }^{\mathrm{a}, \mathrm{c}, \mathrm{d}}$ \\ ${ }^{a}$ Equine Department, Vetsuisse Faculty, University of Zurich, 8057 Zurich, Switzerland \\ ${ }^{\mathrm{b}}$ Institute of Veterinary Physiology, Vetsuisse Faculty, University of Zurich, 8057 Zurich, Switzerland \\ ${ }^{\mathrm{c}}$ Centre for Integrative Human Physiology (ZIHP), University of Zurich, 8057 Zurich, Switzerland \\ ${ }^{\mathrm{d}}$ Centre for Applied Biotechnology and Molecular Medicine (CABMM), University of Zurich, 8057 Zurich, Switzerland
}

\section{A R T I C L E I N F O}

\section{Article history:}

Accepted 20 June 2011

\section{Keywords:}

Equine cardiology

Biomarker

Echocardiography

Atrial enlargement

Ventricular enlargement

\begin{abstract}
A B S T R A C T
Atrial natriuretic peptide (ANP) is a cardiovascular biomarker that might be useful in assessing the severity of cardiac disease in horses. Plasma ANP concentrations $\left(\mathrm{Cp}_{\mathrm{ANP}}\right)$ were compared between horses with heart disease but normal chamber size and function (Group $A ; n=6$ ), horses with heart disease associated with left atrial (LA) enlargement, LA dysfunction, and/or left ventricular (LV) enlargement (Group B; $n=5$ ), and horses with no clinically apparent cardiovascular disease (Group C; $n=13$ ).

The median (min-max) for $\mathrm{Cp}_{\mathrm{ANP}}$ was significantly higher in Group B (53.5 (36.0-70.7) pg/mL), compared to Group A (12.5 (6.3-19.8) pg/mL) and Group C (13.4 (7.2-34.0) pg/mL). Backwards stepwise multiple linear regression showed that $\mathrm{Cp}_{\mathrm{ANP}}$ in horses with heart disease was related to LA dimensions, but not to LV size, LA function, and LV function. The results indicated that $\mathrm{Cp}_{\mathrm{ANP}}$ in horses might be useful in detecting LA enlargement and that $\mathrm{Cp}_{\mathrm{ANP}}$ could be related to the severity of cardiac disease. Larger prospective studies are necessary to confirm these results.
\end{abstract}

(c) 2011 Elsevier Ltd. All rights reserved.

\section{Introduction}

Natriuretic peptides are widely used as cardiac biomarkers in human and veterinary medicine (van Kimmenade and Januzzi, 2009). Physiologically, they counteract the effects of the reninangiotensin-aldosterone system and regulate fluid balance and blood pressure by a variety of renal, vascular, and cardiac mechanisms (McGrath et al., 2005). Natriuretic peptides are produced by atrial and ventricular myocytes and released into the blood in response to a variety of triggers.

The plasma concentration of brain (B-type) natriuretic peptide (BNP; a peptide more abundant in ventricular myocytes) and amino-terminal proBNP (NT-proBNP; the more stable, inactive remnant that is released when BNP is activated from its prohormone proBNP) are most widely used in human medicine, particularly to diagnose diseases associated with ventricular dysfunction and heart failure (Daniels and Maisel, 2007). However, measurement of plasma BNP and NT-proBNP concentrations requires speciesspecific assays, since the amino acid sequence of BNP varies among species (Liu et al., 2002). To date, an assay to measure equine BNP or NT-proBNP concentrations is not commercially available.

\footnotetext{
* Corresponding author. Tel.: +41446358357.

E-mail address: dtrachsel@vetclinics.uzh.ch (D.S. Trachsel).
}

Conversely, the amino acid sequence of atrial natriuretic peptide (ANP) is highly conserved among species, allowing the use of commercially available human assays to measure plasma ANP concentrations ( $\left.\mathrm{Cp}_{\mathrm{ANP}}\right)$ in horses (Richter et al., 1998). ANP is primarily produced by atrial myocytes, although its expression can also be enhanced in diseased ventricular myocytes from experimental animals and in human patients (Ruskoaho, 2003). In addition to atrial stretch or increased pacing frequency, ANP expression and secretion can be increased by a variety of stimuli, including endothelin-1, arginine vasopressin, angiotensin II, $\alpha$-adrenergic agonists, thyroid hormones, glucocorticoids, growth hormone, prostaglandins, vitamin D, thrombin (de Bold et al., 1996; Ruskoaho, 2003) and hypoxia (Chen, 2005). The increased ANP secretion following atrial myocardial stretch due to volume or pressure overload is certainly of particular interest in equine cardiology, since horses frequently suffer from mitral regurgitation (MR) or atrial fibrillation $(\mathrm{AF})$, which both affect atrial size and mechanical function.

Storage of ANP in the equine atrial myocytes and its release during stretching of atrial tissue (as occurring during exercise) has been documented in healthy horses (Mifune et al., 1991; Kokkonen et al., 1995). More recently, it has been shown that $\mathrm{Cp}_{\text {ANP }}$ may be slightly elevated in horses with valvular regurgitation associated with left atrial (LA) enlargement or combined LA and left ventricular (LV) dilation, compared to healthy horses (Gehlen et al., 2007). However, the use of ANP as a cardiac biomarker has not yet been 
fully investigated in horses. It is unknown to what extent $\mathrm{Cp}_{\mathrm{ANP}}$ increases with various heart diseases and whether the measurement of $\mathrm{Cp}_{\mathrm{ANP}}$ is of any diagnostic or prognostic value in horses.

The aim of this study was to measure $\mathrm{Cp}_{\mathrm{ANP}}$ in a group of horses suffering from various heart diseases and to investigate the association between $\mathrm{Cp}_{\mathrm{ANP}}$ and echocardiographic measurements of chamber dimensions and chamber function. We hypothesised that horses with cardiac disease associated with LA enlargement, LA dysfunction, and/or LV enlargement would have increased $\mathrm{Cp}_{\mathrm{ANP}}$ compared to horses with cardiac disease and normal LA and LV size and function and to horses without clinically apparent heart disease.

\section{Material and methods}

\section{Study population}

The main study population consisted of 11 horses that were presented to the Equine Hospital of the Vetsuisse Faculty of the University of Zurich for cardiovascular examination because of existing heart disease (Groups A and B). The population consisted of one female, seven castrated males, and three intact males of various breeds (six Warmbloods, two Arabians, one Thoroughbred, one Friesian, one Paso Fino) with a median age of 14 years (range 3-29 years) and a bodyweight (BW) of $530 \mathrm{~kg}$ (range $360-600 \mathrm{~kg}$ ).

Another group of 13 horses served as control group (Group C). This group had no history and no clinical signs of heart disease, no audible heart murmurs, and no cardiac arrhythmias and was therefore considered free of cardiac disease. No echocardiographic examinations were performed in this group. This group comprised six females, six castrated males, and one intact male of various breeds (six Warmbloods, two Icelandic horses, one Appaloosa, one Palomino, one Zangersheide, one Shire, one Freiberger) with a median age of 8 years (range 3-19 years) and a median BW of $510 \mathrm{~kg}$ (range 400-690 kg; $n=8$ ).

All examinations, including physical examination, and collection of blood samples, were performed within the routine patient workup and therefore did not require approval by the district veterinary office. Owners' consent was obtained.

\section{Echocardiographic examination}

All horses of group A and B underwent a thorough cardiologic examination, including physical examination, thoracic and cardiac auscultation, electrocardiography, and standardised transthoracic two-dimensional (2DE) and M-mode echocardiography (Boon, 1998; Bonagura et al., 2010). Echocardiographic recordings (GE Vivid 7 Dimension (BTO6) with a M4S Phased Array Transducer, GE Healthcare) were obtained by three trained and experienced clinicians within the routine workup of the cases. All measurements were performed offline from the digitally stored cine loop recordings by one single operator (DST) for the purpose of this study.

The echocardiographic examination included conventional 2DE and M-mode measurements of LV dimensions and LV systolic function (Boon, 1998; Bonagura et al., 2010) as well as 2DE measurements of LA dimensions and LA mechanical function using previously described imaging standards (Schwarzwald et al., 2007). Three cardiac cycles were measured and averaged for further analyses. As the study population showed a wide range of BW, the measurements were corrected for differences in weight according to the principles of allometric scaling (Brown et al., 2003; Cornell et al., 2004). Specifically, the measurements of chamber dimensions were normalised to a BW of $500 \mathrm{~kg}$ [500] using the following equations:

Chamber diameter $[500]=$ Measured chamber diameter $/ \mathrm{BW}^{1 / 3} \times 500^{1 / 3}$

\section{Chamber area $[500]=$ Measured chamber area $/ \mathrm{BW}^{2 / 3} \times 500^{2 / 3}$}

Linear echocardiographic indices of LA and LV size included maximum LA diameter measured in a right parasternal long-axis $2 \mathrm{DE}$ recording at end-systole $\left(\mathrm{LAD}_{\max }\right) ; \mathrm{LAD}_{\max }$ normalised to a $\mathrm{BW}$ of $500 \mathrm{~kg}\left(\mathrm{LAD}_{\max }[500]\right)$; left ventricular internal diameter at end-diastole $\left(\operatorname{LVID}_{\mathrm{d}}\right)$ and peak systole $\left(\operatorname{LVID}_{\mathrm{s}}\right)$ measured in a right parasternal short-axis $\mathrm{M}$-mode recording at the level of the chordae tendineae; and VVID $_{\mathrm{d}}$ normalised to a BW of $500 \mathrm{~kg}\left(\operatorname{LVID}_{\mathrm{d}}[500]\right)$.

Uni-dimensional (linear) indices of LA function are not considered reliable (Schwarzwald et al., 2007) and therefore were not calculated in this study. The LV fractional shortening (LV FS) was calculated as a uni-dimensional index of LV function based on M-mode measurements of the LVID (LV FS $=\left(\operatorname{LVID}_{\mathrm{d}}-\mathrm{LVID}_{\mathrm{s}}\right)$ ) LVID $_{\mathrm{d}} \times 100$ ).

Two-dimensional (area-based) indices of LA and LV size included maximum LA area measured in a right parasternal long-axis 2DE recording at end-systole $\left(\mathrm{LAA}_{\max }\right) ; \mathrm{LAA}_{\max }$ normalised to a $\mathrm{BW}$ of $500 \mathrm{~kg}$ ( $\mathrm{LAA}_{\max }$ [500]); LA area prior to active contraction measured in a right parasternal long-axis 2DE recording at the onset of the electrocardiographic P wave $\left(\mathrm{LAA}_{\mathrm{a}}\right)$; minimum LA area measured in a right parasternal long-axis 2DE recording at the time of mitral valve closure (LAAmin); maximum LA area measured in a right parasternal short-axis 2DE recording at end-systole $\left(\mathrm{LA}_{\mathrm{sx}} \mathrm{A}_{\max }\right) ; \mathrm{LA}_{\mathrm{sx}} \mathrm{A}_{\max }$ normalised to a $\mathrm{BW}$ of $500 \mathrm{~kg}\left(\mathrm{LA}_{\mathrm{Sx}} \mathrm{A}_{\max }[500]\right) ; \mathrm{LV}$ internal area measured in a right parasternal long-axis $2 D E$ recording at end-diastole $\left(\mathrm{LVIA}_{d}\right)$ and at peak systole $\left(\mathrm{LVIA}_{\mathrm{s}}\right)$; and $\mathrm{LVIA}_{\mathrm{d}}$ normalised to a $\mathrm{BW}$ of $500 \mathrm{~kg}$ (LVIA $[$ [500]).

Two-dimensional (area-based) indices of LA and LV function included active fractional area change of the LA (Active LA FAC $\left.=\left(\mathrm{LAA}_{\mathrm{a}}-\mathrm{LAA}_{\min }\right) / \mathrm{LAA}_{\mathrm{a}} \times 100\right)$; passive fractional area change of the LA (Passive $L A F A C=\left(L A A_{\max }-\mathrm{LAA}_{\mathrm{a}}\right)$ ) $\left.\mathrm{LAA}_{\max } \times 100\right)$; active-to-total LA area change (active:total LA AC $=\left(\mathrm{LAA}_{\mathrm{a}}-\mathrm{LAA}_{\min }\right) /$ $\left.\left(L A A_{\max }-L A A_{\min }\right)\right)$; and fractional area change of the LV based on long-axis 2DE measurements of LVIA $\left(\right.$ LV FAC $=\left(\right.$ LVIA $_{d}-$ LVIA $\left.\left._{s}\right) / L_{\text {LVIA }} \times 100\right)$.

Grading of valvular regurgitations was based on a subjective grading scale (1-9) considering the high-velocity jet area, the regurgitant signal duration, and the number of imaging planes in which the high-velocity jet could be observed in the receiving chamber (Young et al., 2008). The diagnosis of LA and LV enlargement and/or dysfunction was based on the consensus of two independent observers (DST, CCS). In addition to subjective assessment, quantitative indices of LA and LV size and function were measured or calculated as described above and (where available for the respective breed and body size) compared to reference ranges published in the literature (Boon, 1998; Schwarzwald et al., 2007; Bonagura et al., 2010) and/or established in our echocardiography laboratory. During echocardiographic recordings, offline analyses, and final assessment, the observers were blinded to the results of the $\mathrm{Cp}_{\mathrm{ANP}}$ measurements.

Signalment, diagnoses, and echocardiographic indices of all horses are listed in Table 1 . Six horses had normal LA and LV dimensions and mechanical function by echocardiography (Group A). One of the horses had MR, two had aortic regurgitation (AR), one had AR and a restrictive ventricular septal defect (VSD), one showed both AR and MR, and one showed MR, AR, and traces of tricuspid regurgitation (TR) and pulmonic regurgitation (PR). Five horses suffered from cardiac disease associated with LA enlargement, LA dysfunction, and/or LV enlargement (Group B). In this group, one horse had LA dysfunction associated with chronic AF (lasting at least 1 year) without concomitant valvular diseases and without LA and LV enlargement, one horse had moderate to severe AR and trivial to mild MR with an enlarged LV but normal LA size and function, and three horses had increased LV dimensions concomitant to LA enlargement and/or LA dysfunction, associated with multiple valvular regurgitations, AF, and aorto-cardiac fistula, respectively. Two horses in Group B showed signs of congestive heart failure (CHF).

\section{Blood sampling}

The very short half-life time (estimated to be approximately 2-5 min in sheep and humans (Biollaz et al., 1987; Mukaddam-Daher et al., 1994) warranted careful and immediate sample processing. Hence, blood samples were taken by jugular venepuncture and placed into prepared blood tubes containing potassium-EDTA (1.6 mg EDTA $/ \mathrm{mL}$ blood, Sarstedt) and aprotinine (lyophilised aprotinine ( $600 \mathrm{KIU} / \mathrm{mL}$ blood), Sigma-Aldrich). They were then immediately cooled on ice and centrifuged for $5 \mathrm{~min}$ at $1570 \mathrm{~g}$ and $4{ }^{\circ} \mathrm{C}$. Plasma was then harvested, transferred into cryovials (TTP Techno Plastic Products), and frozen at $-80^{\circ} \mathrm{C}$ within $15 \mathrm{~min}$ after sampling.

\section{Laboratory analysis}

Human ANP has previously been shown to be stable at $-80^{\circ} \mathrm{C}$ for at least 12 months (Zolty et al., 2008). All samples were therefore analysed within 12 months after collection. The ANP was extracted and measured using a commercially available radioimmunoassay (RIA) kit (RIA kit RK-005-06: ANP $\alpha$ (1-28), Phoenix Pharmaceuticals) and a gamma-counter (GAMMAmatic I, Kontron Analytical, $\mathrm{W}+\mathrm{W}$ Electronic AG), following the manufacturer's instructions. The target sequence recognised by the assay has previously been shown to be $100 \%$ homologous in horses and humans (Richter et al., 1998).

\section{Data analyses and statistics}

Data analyses and statistics were performed using commercial computer software (GraphPad Prism, version 5.03, GraphPad Software, SigmaStat, version 3.5, Systat Software). Because of the low sample size within the groups, no normality tests were performed and non-parametric statistics were chosen. Continuous variables were summarised using medians and ranges. The $\mathrm{Cp}_{\mathrm{ANP}}$ of the three Groups were compared using a Kruskal-Wallis one-way analysis of variance with Dunn's post hoc test for multiple comparisons. Backwards stepwise multiple linear regression analyses were performed including all horses in Groups A and B to assess the relationship between $\mathrm{Cp}_{\text {ANP }}$ and weight-corrected echocardiographic indices of LA and LV size and function. Linear measurements and area measurements were analysed separately. Measurements of LA and LV dimensions were forced into the equation, whereas the indices of LA and LV systolic function were allowed to be eliminated by the backwards stepwise regression model. The level of significance was set at $P<0.05$. 


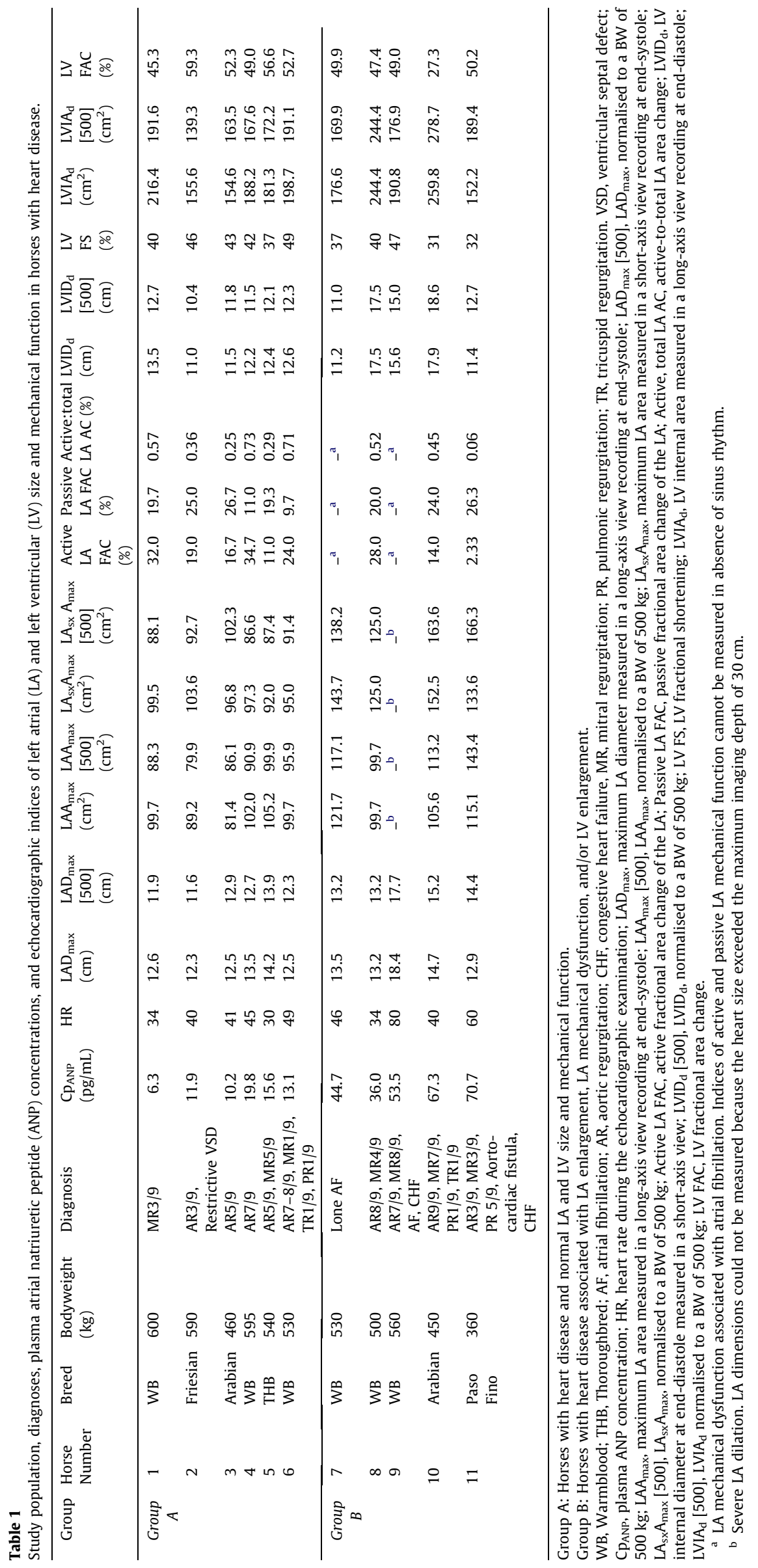




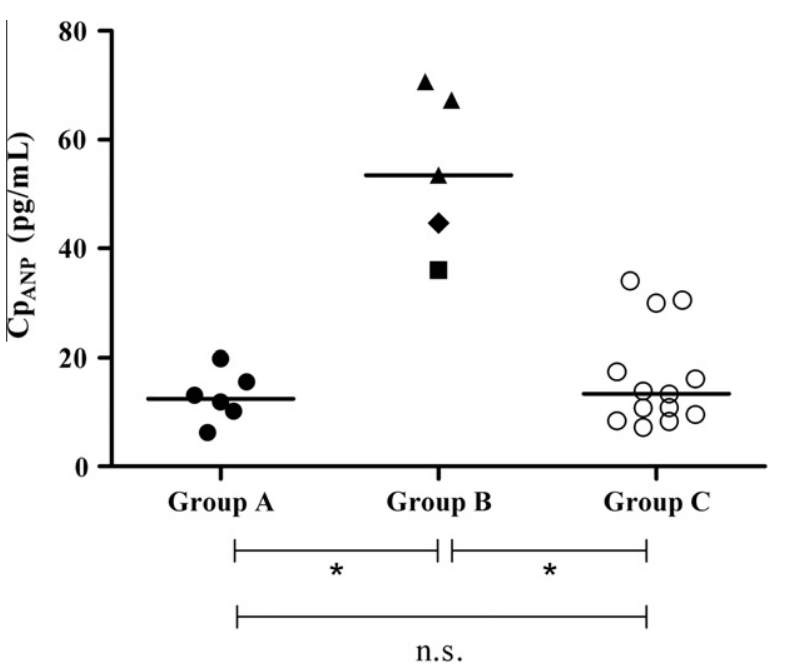

Fig. 1. Plasma atrial natriuretic peptide (ANP) concentrations $\left(\mathrm{Cp}_{\mathrm{ANP}}\right)$. Group $\mathrm{A}$ : Horses with heart disease but normal left atrial (LA) and left ventricular (LV) size and mechanical function. Group B: Horses with heart disease associated with LA enlargement, LA dysfunction, and/or LV enlargement; $\bullet$, horse with LA dysfunction because of lone atrial fibrillation (AF) but normal LA and LV dimensions; $\mathbf{a}$, horse with LV enlargement but normal LA size and mechanical function. Group C: Horses without history or clinical sings of heart disease. The horizontal lines represent the median $\mathrm{Cp}_{\mathrm{ANP}}$ in each group. ${ }^{*} P<0.05$; n.s., not significant.
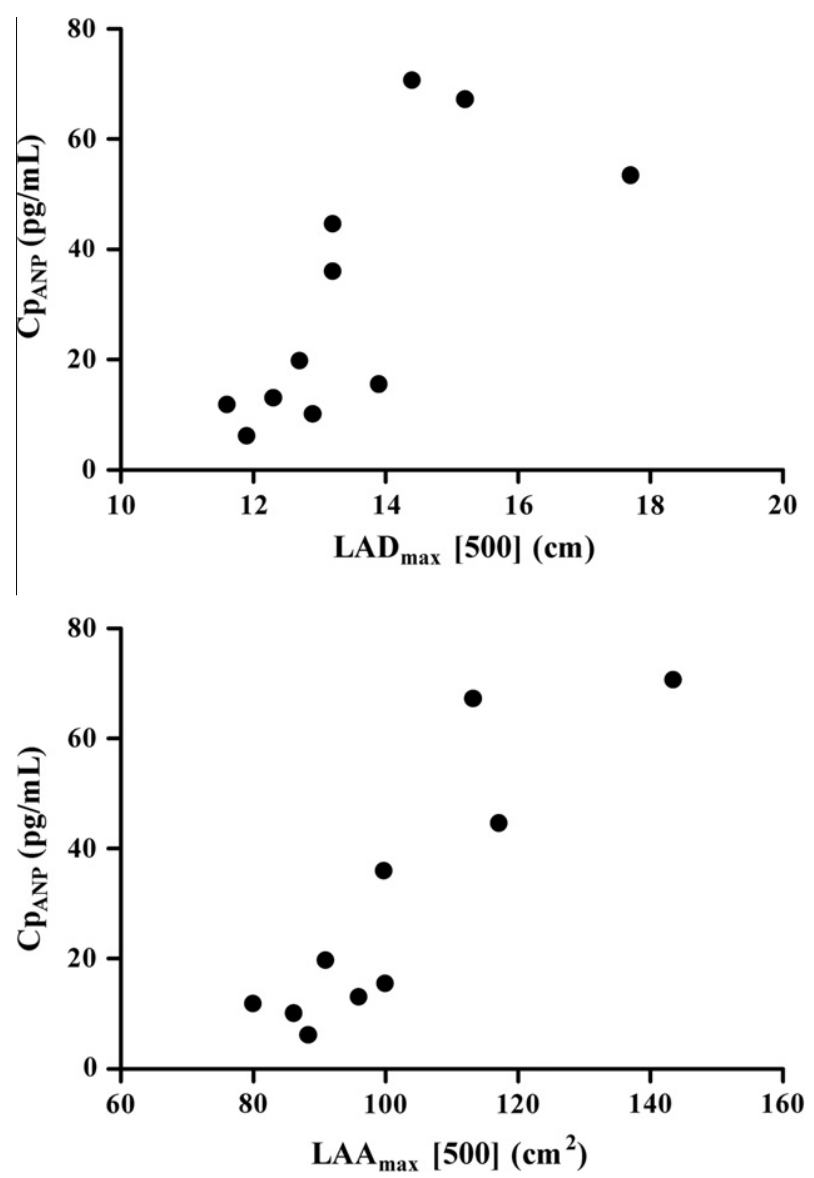

Fig. 2. Plasma ANP concentration ( $\left(\mathrm{C}_{\mathrm{ANP}}\right)$ in relation to LA diameter and $\mathrm{LA}$ area, respectively. $\mathrm{LAD}_{\max }$ [500], Maximum LA diameter measured in a right parasternal long-axis view recording at end-systole normalised to a $\mathrm{BW}$ of $500 \mathrm{~kg}$. $\mathrm{LAA} \mathrm{A}_{\max }$ [500], Maximum LA area measured in a right parasternal long-axis view recording at endsystole, normalised to a BW of $500 \mathrm{~kg}$.

\section{Results}

The $\mathrm{Cp}_{\mathrm{ANP}}$ expressed as median (min-max) in Group A, B and C were 12.5 (6.3-19.8), 53.5 (36.0-70.7), and $13.4(7.2-34.0) \mathrm{pg} / \mathrm{mL}$, respectively (Fig. 1, Table 1 ). The $\mathrm{Cp}_{\mathrm{ANP}}$ in Group B was significantly higher compared to Groups A and $C$, respectively $(P<0.05)$. There was no statistically significant difference in $\mathrm{Cp}_{\mathrm{ANP}}$ between Group A and Group C.

The multiple regression analysis showed that $\mathrm{Cp}_{\mathrm{ANP}}$ could be predicted from $\operatorname{LAD}_{\max }[500](P=0.033)$, whereas the $\operatorname{LVID}_{\mathrm{d}}[500]$ $(P=0.743)$ and LV FS $(P=0.056)$ did not significantly add to the ability of equation to predict $C \mathrm{p}_{\mathrm{ANP}}$. Similarly, the $\mathrm{Cp}_{\mathrm{ANP}}$ could be predicted from $L^{2 A A_{\max }}$ [500] $(P=0.003)$, whereas the effect of LVIA $_{d}[500](P=0.074)$ was not significant. Active LA FAC and LV FAC did not significantly add to the ability of the equation to predict $\mathrm{Cp}_{\mathrm{ANP}}$ and were removed from the model during the stepwise procedure. The power of the performed tests was 0.961 for linear indices and 0.987 for area indices. The relations of $\mathrm{LAD}_{\max }$ [500] and $\mathrm{LAA}_{\max }[500]$, respectively, to $\mathrm{Cp}_{\mathrm{ANP}}$ are shown in Fig. 2 .

\section{Discussion}

The results of this study indicated that $\mathrm{Cp}_{\mathrm{ANP}}$ was increased in horses with cardiac disease associated with cardiac chamber enlargement and/or dysfunction and that $\mathrm{CP}_{\mathrm{ANP}}$ was directly related to the degree of LA enlargement.

The study population consisted of a group of horses with cardiac disease and normal LA and LV dimensions and mechanical function by echocardiography (Group A) and a group of horses with cardiac disease associated with LA enlargement, LA dysfunction, and/or LV enlargement (Group B). In Group A, the $\mathrm{Cp}_{\mathrm{ANP}}$ was slightly lower than values reported by Gehlen et al. (2007) in Warmblood horses with valvular regurgitation and normal chamber dimensions $(20.1 \pm 5.6 \mathrm{pg} / \mathrm{mL}$, mean $\pm \mathrm{SD})$. In the latter study, $C \mathrm{p}_{\mathrm{ANP}}$ in this group was not significantly different from $\mathrm{Cp}_{\mathrm{ANP}}$ in healthy Warmblood horses $(21.0 \pm 5.4 \mathrm{pg} / \mathrm{mL}$ ) (Gehlen et al., 2007). Similarly, in our study there was no difference in $\mathrm{Cp}_{\text {ANP }}$ between Group A and Group C (control group). Furthermore, $\mathrm{Cp}_{\mathrm{ANP}}$ in our control group was similar to the concentrations reported by Gehlen et al. (2007) in healthy Warmblood horses and similar to those reported in healthy Finnhorse trotters $(18 \pm$ $1 \mathrm{pg} / \mathrm{mL}$, mean $\pm \mathrm{SE})$ and healthy Standardbreds $(15 \pm 2 \mathrm{pg} / \mathrm{mL}$, mean \pm SE) (Kokkonen et al., 1995). It could therefore be inferred that horses with cardiac disease and normal chamber dimensions could not reliably be differentiated from healthy horses by use of Cp AnP. $_{\text {. }}$

Conversely, $\mathrm{Cp}_{\mathrm{ANP}}$ may be suitable to identify left-sided chamber enlargement or dysfunction in horses with cardiac disease, since the $\mathrm{Cp}_{\mathrm{ANP}}$ in Group B was significantly higher compared to Group A, with no overlap between groups seen in this study. Notably, $\mathrm{Cp}_{\mathrm{ANP}}$ in Group B was markedly higher than the $\mathrm{Cp}_{\mathrm{ANP}}$ reported by Gehlen et al. (2007) in horses with enlarged LA but normal LV dimensions $(22.9 \pm 11.0 \mathrm{pg} / \mathrm{mL})$, and in horses with both LA and LV enlargement $(27.6 \pm 17.4 \mathrm{pg} / \mathrm{mL})$, neither of which was significantly different from healthy Warmblood horses $(21.0 \pm 5.4 \mathrm{pg} / \mathrm{mL})$ in the aforementioned study.

The linear regression model revealed that $\mathrm{Cp}_{\mathrm{ANP}}$ in horses with cardiac disease was significantly related to LA dimensions, but not to LV dimensions or indices of LA and LV systolic function. The absence of a significant influence of LV dimensions in our study population was interesting, as enhanced ANP expression has been demonstrated in ventricular disease in experimental models and in human patients (Ruskoaho, 2003). However, this study only included a small number of horses and might not have allowed identifying all influencing factors. Furthermore, the influence of LA 
dysfunction could not be assessed thoroughly as there was only one horse with LA dysfunction because of lone AF. Therefore, larger studies including horses with a wide spectrum of disease severity will be necessary to confirm these findings and to conclusively determine the relative influence of LA and LV enlargement and mechanical dysfunction as well as right heart enlargement and dysfunction on $\mathrm{Cp}_{\mathrm{ANP}}$.

In the current study, the relation of $\mathrm{Cp}_{\mathrm{ANP}}$ to the two-dimensional area measurements seemed to be slightly stronger than the relation to the linear measurements. This might be explained by the fact that area measurements better represent LA dimensions, compared to linear measurements (Lang et al., 2006; Schwarzwald et al., 2007). This supported our contention that area measurements should be preferred or at least used in addition to linear measurements for echocardiographic quantification of chamber dimensions and chamber function in studies on cardiac biomarkers.

The absence of a well defined control group consisting of healthy horses without cardiac disease, as confirmed by echocardiography, was one of the limitations of this study. Furthermore, only a relatively small number of horses with a variety of cardiac disorders were enrolled. Therefore, the results did not permit a comprehensive assessment of the diagnostic value of $\mathrm{Cp}_{\mathrm{ANP}}$ in specific cardiac diseases, nor did they clearly differentiate the effects of atrial vs. ventricular enlargement on $\mathrm{Cp}_{\mathrm{ANP}}$.

\section{Conclusions}

The results of this study indicated that measurement of $\mathrm{Cp}_{\mathrm{ANP}}$ in horses provides potentially useful data on cardiac chamber dimensions and that $\mathrm{Cp}_{\mathrm{ANP}}$ might be related to the severity of disease in horses with cardiac disorders. Larger prospective clinical studies are required to determine the diagnostic and prognostic value of ANP in horses with cardiac disease.

\section{Conflict of interest statement}

None of the authors of this paper has a financial or personal relationship with other people or organisations that could inappropriately influence or bias the content of the paper.

\section{Acknowledgments}

We acknowledge Drs. K. Geser-von Peinen and C. Bitschnau, collaborators of the Equine Performance Centre of the Vetsuisse Faculty of the University of Zurich, for their assistance.

\section{References}

Biollaz, J., Callahan 3rd, L.T., Nussberger, J., Waeber, B., Gomez, H.J., Blaine, E.H., Brunner, H.R., 1987. Pharmacokinetics of synthetic atrial natriuretic peptides in normal men. Clinical Pharmacology and Therapeutics 41, 671-677.

Bonagura, J.D., Reef, V.B., Schwarzwald, C.C., 2010. Cardiovascular diseases. In: Reed, S.M., Bayly, W.M., Sellon, D.C. (Eds.), Equine Internal Medicine. Saunders, St. Louis, MO, pp. 372-487.

Boon, J.A., 1998. Manual of Veterinary Echocardiography. Lippincott Williams \& Wilkins, Baltimore, MD.

Brown, D.J., Rush, J.E., MacGregor, J., Ross Jr., J.N., Brewer, B., Rand, W.M., 2003. M-mode echocardiographic ratio indices in normal dogs, cats, and horses: A novel quantitative method. Journal of Veterinarian Internal Medicine 17, 653-662.

Chen, Y.F., 2005. Atrial natriuretic peptide in hypoxia. Peptides 26, 1068-1077.

Cornell, C.C., Kittleson, M.D., Della Torre, P., Haggstrom, J., Lombard, C.W., Pedersen, H.D., Vollmar, A., Wey, A., 2004. Allometric scaling of M-mode cardiac measurements in normal adult dogs. Journal of Veterinary Internal Medicine 18, 311-321.

Daniels, L.B., Maisel, A.S., 2007. Natriuretic peptides. Journal of the American College of Cardiology 50, 2357-2368.

de Bold, A.J., Bruneau, B.G., Kuroski de Bold, M.L., 1996. Mechanical and neuroendocrine regulation of the endocrine heart. Cardiovascular Research 31, 7-18.

Gehlen, H., Sundermann, T., Rohn, K., Stadler, P., 2007. Plasma atrial natriuretic peptide concentration in Warmblood horses with heart valve regurgitations. Journal of Veterinary Cardiology 9, 99-101.

Kokkonen, U.M., Hackzell, M., Räsänen, L.A., 1995. Plasma atrial natriuretic peptide in Standardbred and Finnhorse trotters during and after exercise. Acta Physiologica Scandinavica 154, 51-58.

Lang, R.M., Bierig, M., Devereux, R.B., Flachskampf, F.A., Foster, E., Pellikka, P.A., Picard, M.H., Roman, M.J., Seward, J., Shanewise, J., Solomon, S., Spencer, K.T., St John Sutton, M., Stewart, W., 2006. Recommendations for chamber quantification. European Journal of Echocardiography 7, 79-108.

Liu, Z.L., Wiedmeyer, C.E., Sisson, D.D., Solter, P.F., 2002. Cloning and characterization of feline brain natriuretic peptide. Gene 292, 183-190.

McGrath, M.F., de Bold, M.L., de Bold, A.J., 2005. The endocrine function of the heart. Trends in Endocrinology and Metabolism 16, 469-477.

Mifune, H., Suzuki, S., Noda, Y., Mohri, S., Mochizuki, K., 1991. Fine structure of atria natriuretic peptide (ANP)-granules in the atrial cardiocytes in the pig, cattle and horse. The Journal of Veterinary Medical Science 53, 561-568.

Mukaddam-Daher, S., Gutkowska, J., Nuwayhid, B.S., Quillen Jr., E.W., 1994 Metabolic clearance of atrial natriuretic factor in ovine pregnancy. The American Journal of Physiology 267, R1413-1420.

Richter, R., Mägert, H.J., Mifune, H., Schulz-Knappe, P., Forssmann, W.G., 1998. Equine cardiodilatin/atrial natriuretic peptide. Primary structure and immunohistochemical localization in auricular cardiocytes. Acta Anatomica $162,185-193$

Ruskoaho, H., 2003. Cardiac hormones as diagnostic tools in heart failure. Endocrine Reviews 24, 341-356.

Schwarzwald, C.C., Schober, K.E., Bonagura, J.D., 2007. Methods and reliability of echocardiographic assessment of left atrial size and mechanical function in horses. American Journal of Veterinary Research 68, 735-747.

van Kimmenade, R.R., Januzzi Jr., J.L., 2009. The evolution of the natriuretic peptides - current applications in human and animal medicine. Journal of Veterinary Cardiology 11, S9-S21.

Young, L.E., Rogers, K., Wood, J.L., 2008. Heart murmurs and valvular regurgitation in Thoroughbred racehorses: Epidemiology and associations with athletic performance. Journal of Veterinary Internal Medicine 22, 418-426.

Zolty, R., Bauer, C., Allen, P., Garrity, M., Vittorio, T.J., 2008. Atrial natriuretic peptide stability. Clinical Biochemistry 41, 1255-1258. 